\title{
Study and Simulation Design of various Three Mode Controller for an Interacting System
}

\author{
Janani $\mathbf{R}^{1}$ \\ ${ }^{1}$ Assistant Professor - Electronics and Instrumentation Engineering, Sri Chandrasekharendra Saraswathi Viswa \\ Mahavidyalaya, Enathur, Tamilnadu
}

\begin{abstract}
The main objective of this research work is to study the various conventional three mode controller algorithm for an interacting and non-interacting liquid level two tank system. For controlling any chemical process, a mathematical model is identified, suitable controller is designed and simulated to get the desired process behaviour. For this purposes, a lab scale interacting and non-interacting liquid tank system is considered. The mathematical transfer function model is obtained and various conventional PID controller algorithm are simulated, the efficiency of the methods are demonstrated in simulation using Matlab/Simulink software. The closed loop performance measure are calculated and tabulated. The simulation results shows that the conventional PID controller algorithm has good setpoint tracking and performance
\end{abstract}

Keywords: interacting system, non-interacting system, conventional PID, SISO system.

\section{INTRODUCTION}

The first stage in the development of any control and monitoring system is the identification and modeling of the system. The present work is concerned with developing Mathematical model for interacting and non-interacting tank process and comparison of various conventional PID control algorithms. The control of liquid level in multiple tanks and flow of liquid between the tanks is the basic problem in process industries. Level process is one of the most common processes employed in any chemical industries [1,2] Maintaining the level of the liquid in a process at certain level in spite of the disturbance is the complex in nature. Level process may consists of single tank or multiple tank which is very difficult to analyse and control.

\section{SYSTEM MODELLING}

Change in level difference between the two tanks which causes a unit change in flow rate is defined as Resistance (R). Any change in quantity to store liquid to cause a unit change in potential head is defined as Capacitance. Resistance and capacitance are the two basic terms used in a two tank liquid level tank system. Consider the interacting and noninteracting system shown in Figure 1. The inlet flow rate and the outlet flow rate for tank 1 and tank 2 are considered in order to obtain the transfer function of the process. Consider the two tank system the inlet flow rate is given as $\mathrm{q}_{\mathrm{i}}$, the outlet flow rate is given as $\mathrm{q}_{1}, \mathrm{q}_{2}$ for tank 1 and tank 2 respectively. The level and area of the tank1 and tank 2 are $\mathrm{h}_{1}, \mathrm{a}_{1}$ and $\mathrm{h}_{2}, \mathrm{a}_{2}$ respectively. The mathematical model can be obtained as for tank 1

$$
\begin{aligned}
\mathrm{A}_{1} \frac{\mathrm{dh}_{1}}{\mathrm{dt}} & =\mathrm{q}_{\mathrm{in}}-\mathrm{q}_{1} \\
\mathrm{q}_{1} & =\frac{\mathrm{h}_{1}}{\mathrm{R}_{1}} \\
\mathrm{~A}_{1} \frac{\mathrm{dh}_{1}}{\mathrm{dt}} & =\mathrm{q}_{\mathrm{in}}-\frac{\mathrm{h}_{1}}{\mathrm{R}_{1}}
\end{aligned}
$$

Taking Laplace Transform

$$
\frac{\mathrm{H}_{1}(\mathrm{~s})}{\mathrm{Q}_{\text {in }}(\mathrm{s})}=\frac{\mathrm{R}_{1}}{\mathrm{~A}_{1} \mathrm{R}_{1} \mathrm{~s}+1}
$$

For Tank 2

$$
A_{2} \frac{d h_{2}}{d t}=q_{1}-q_{2}
$$

$\mathrm{q}_{1}=\frac{\mathrm{h}_{1}}{\mathrm{R}_{1}} ; \quad \mathrm{q}_{2}=\frac{\mathrm{h}_{2}}{\mathrm{R}_{2}}$

Taking Laplace Transform

$$
\frac{\mathrm{H}_{1}(\mathrm{~s})}{\mathrm{Q}_{\text {in }}(\mathrm{s})}=\frac{\mathrm{R}_{1}}{\mathrm{~A}_{1} \mathrm{R}_{1} \mathrm{~s}+1}
$$


Taking Laplace Transform

$$
\mathrm{A}_{2} \frac{\mathrm{dh}_{2}}{\mathrm{dt}}=\frac{\mathrm{h}_{1}}{\mathrm{R}_{1}}-\frac{\mathrm{h}_{2}}{\mathrm{R}_{2}}
$$

$$
\mathrm{A}_{2} \mathrm{sH}_{2}(\mathrm{~s})=\frac{\mathrm{H}_{1}(\mathrm{~s})}{\mathrm{R}_{1}}-\frac{\mathrm{H}_{2}(\mathrm{~s})}{\mathrm{R}_{2}}
$$

Substituting (4) in (9)

$$
\frac{\mathrm{H}_{2}(\mathrm{~s})}{\mathrm{Q}_{\text {in }}(\mathrm{s})}=\frac{\mathrm{R}_{2}}{\left(1+\mathrm{A}_{1} \mathrm{R}_{1} \mathrm{~s}\right)\left(1+\mathrm{A}_{2} \mathrm{R}_{2} \mathrm{~s}\right)}
$$

By considering the following design parameters specified in Table 1, the transfer function of the non-interacting liquid level system is obtained as $[3,4]$

$$
\frac{\mathrm{H}_{2}(\mathrm{~s})}{\mathrm{Q}_{\text {in }}(\mathrm{s})}=\frac{0.01 \mathrm{e}^{-3.7 \mathrm{~s}}}{5.5 \mathrm{~s}+1}
$$

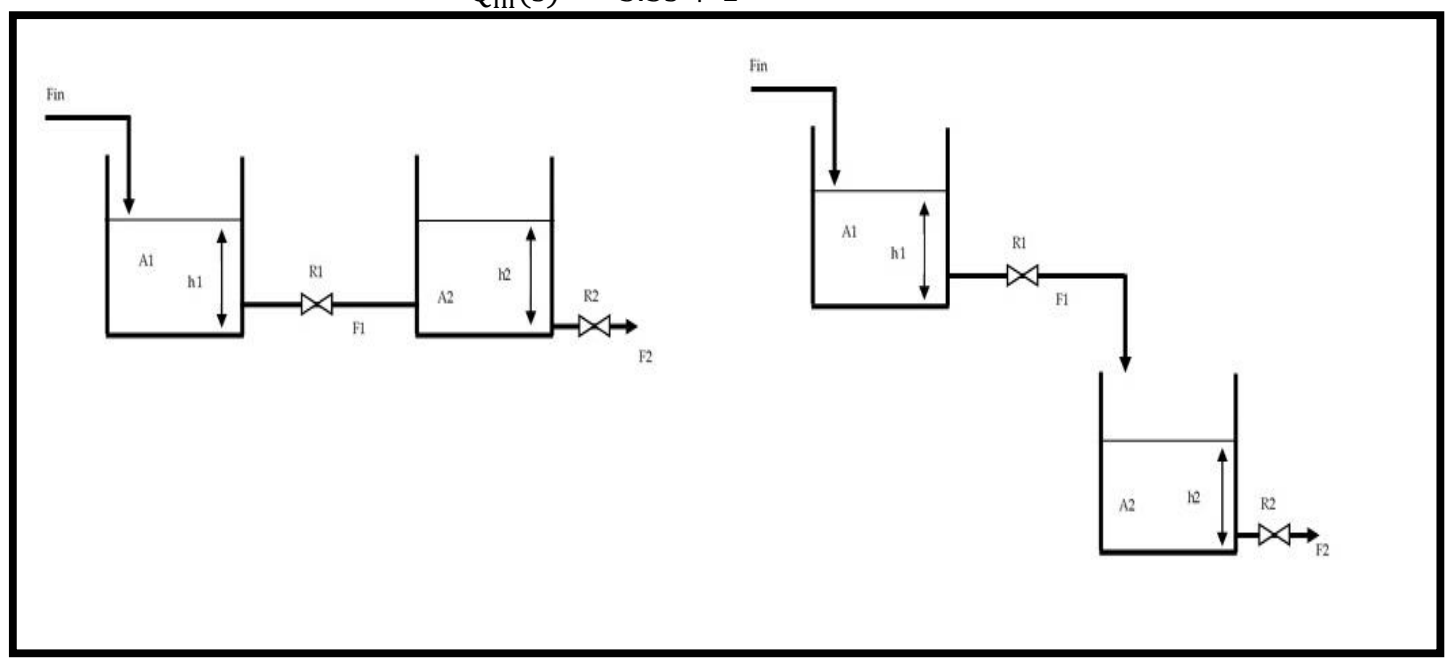

Fig 1. Two-Tank Liquid Level Process

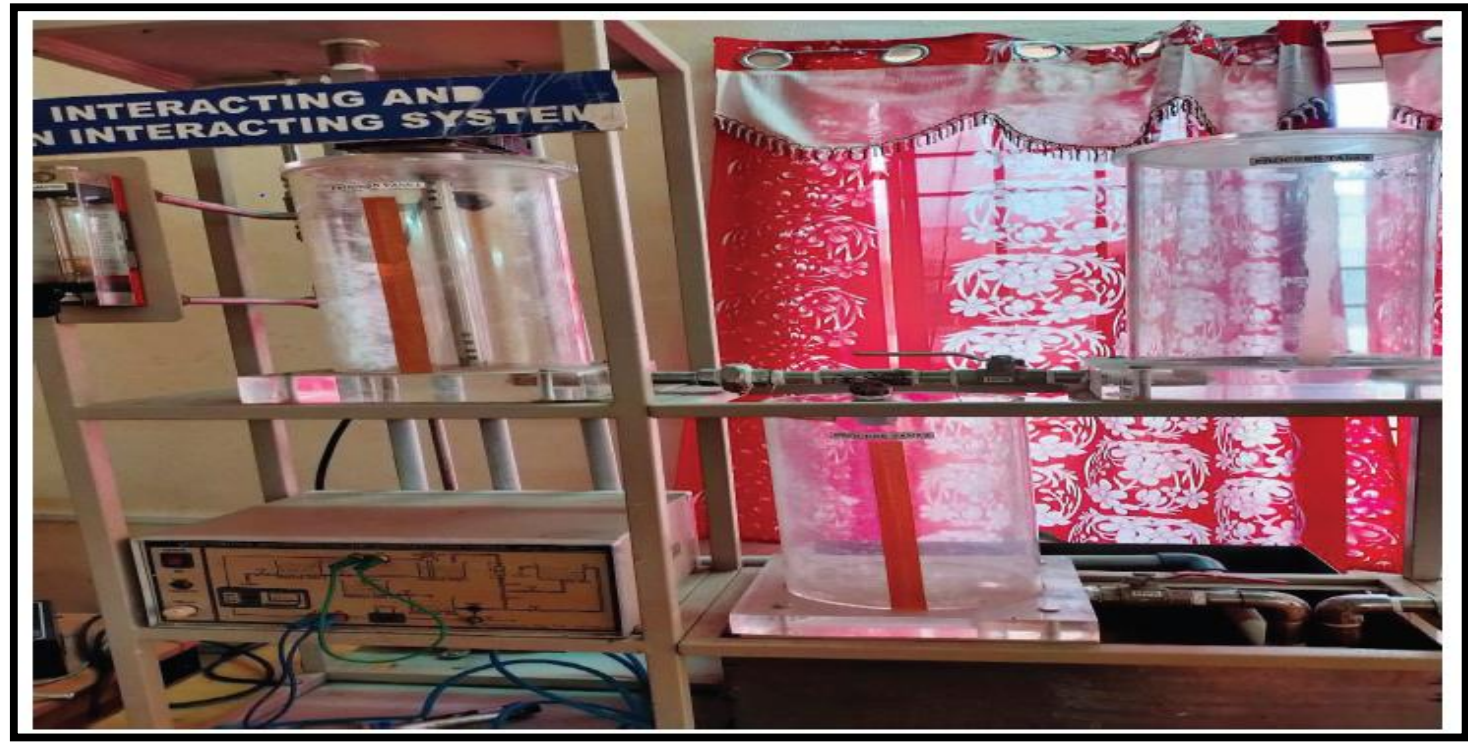

Fig 2. Lab-Scale Interacting and Non-Interacting System

\section{CONVENTIONAL THREE MODE CONTROLLER}

PID Controller is a reliable controller which is implemented in many fields, such as robotics and industry. PID control is one of the conventional control algorithms that are widely used in process control because it has a relatively simple structure and good performance over a wide area of operation [5, 6]. To remove the offset and overshoot created by proportional gain, integral gain is introduced. PID control offers the high flexibility to achieve the desired controlled 


\section{International Advanced Research Journal in Science, Engineering and Technology}

Vol. 8, Issue 9, September 2021

DOI: $10.17148 /$ IARJSET.2021.8942

response. PID controller increases the speed of the closed loop response and retain robustness. For a multicapacity process whose response is very sluggish the addition of a PI controller makes it even more sluggish. The addition of derivative control action with its stabilizing effect allows the use of higher gains which produce faster response without excessive oscillations. The relationship between the input $\mathrm{e}(\mathrm{t})$ and output $\mathrm{u}(\mathrm{t})$ can be formulated in the following

$$
U(t)=K_{P} e(t)+K_{I} \int_{0}^{t} e(t) d t+K_{D} \frac{d e(t)}{d t}
$$

A general PID controller system block diagram is shown in

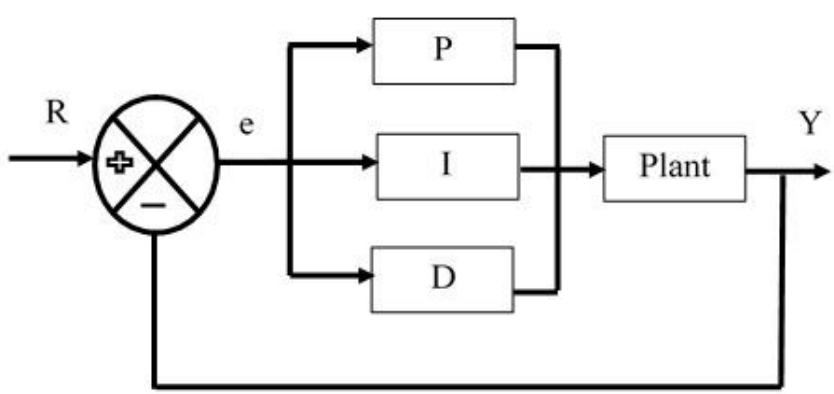

Fig 3. Block Diagram PID Controller Design

PID Controllers are tuned in terms of Proportional gain, Integral gain and Derivative gain. ZN method is a type of continuous cycling method for controller tuning. This method is based on the continuous oscillation with constant amplitude and also based on the trial and error procedure of changing the proportional gain [7, 8]. Initially the proportional gain $\mathrm{Kp}$ is varied from 0 till the system reaches unstable i.e. system continues to oscillate. The gain at which system starts [9-10] oscillating is called as Ultimate gain $(\mathrm{Ku})$ and period of oscillation is called as Ultimate period $(\mathrm{Pu})$. The tuning parameters are

\subsection{Arrieta Orozco:}

$$
\begin{gathered}
\mathrm{K}_{\mathrm{c}}=0.6 \mathrm{~K}_{\mathrm{u}} \\
\mathrm{T}_{\mathrm{i}}=0.5 \mathrm{P}_{\mathrm{u}} \\
\mathrm{T}_{\mathrm{d}}=0.125 \mathrm{P}_{\mathrm{u}}
\end{gathered}
$$
given by

The closed loop response without any overshoot has been assumed. The resulting feedback PID controller is

\subsection{Syrcos \& Kookos:}

$$
\begin{gathered}
\mathrm{K}_{\mathrm{c}}=\frac{1}{\mathrm{~K}_{\mathrm{m}}}\left[0.2068+1.1597\left(\frac{\mathrm{T}_{\mathrm{m}}}{\tau_{\mathrm{m}}}\right)^{1.0158}\right] \\
\mathrm{T}_{\mathrm{i}}=\mathrm{T}_{\mathrm{m}}\left[-0.2228+1.3009\left(\frac{\tau_{\mathrm{m}}}{\mathrm{T}_{\mathrm{m}}}\right)^{0.5022}\right] \\
\mathrm{T}_{\mathrm{d}}=0.3953 \mathrm{~T}_{\mathrm{m}}\left[\left(\frac{\tau_{\mathrm{m}}}{\mathrm{T}_{\mathrm{m}}}\right)^{0.8469}\right]
\end{gathered}
$$

\subsection{Fruehauf Method:}

$$
\begin{gathered}
\mathrm{K}_{\mathrm{c}}=\frac{1}{\mathrm{~K}_{\mathrm{m}}}\left[0.31+0.6\left(\frac{\mathrm{T}_{\mathrm{m}}}{\tau_{\mathrm{m}}}\right)\right] \\
\mathrm{T}_{\mathrm{i}}=\mathrm{T}_{\mathrm{m}}\left[0.777+0.45\left(\frac{\tau_{\mathrm{m}}}{\mathrm{T}_{\mathrm{m}}}\right)\right] \\
\mathrm{T}_{\mathrm{d}}=\mathrm{T}_{\mathrm{m}}\left[0.44-0.56\left(\frac{\mathrm{T}_{\mathrm{m}}}{\tau_{\mathrm{m}}}\right)^{2.2}\right]
\end{gathered}
$$

The closed loop response without any overshoot has been assumed. The resulting feedback PID controller is given by

$$
\begin{gathered}
\mathrm{K}_{\mathrm{c}}=\frac{0.56 \mathrm{~T}_{\mathrm{m}}}{\mathrm{K}_{\mathrm{m}} \tau_{\mathrm{m}}} \\
\mathrm{T}_{\mathrm{i}}=5 \mathrm{~T}_{\mathrm{m}} \\
\mathrm{T}_{\mathrm{d}}=0.5 \tau_{\mathrm{m}}
\end{gathered}
$$




\section{SIMULATION RESULTS}

The simulation of liquid level thank system is carried out, Figure. 4 and Figure 5 shows the Servo and Regulatory close loop step response. The simulation results show that the conventional controller show good set point tracking. Table 1 shows value of the tuning parameters of various conventional PID controllers. Table 2 shows the performance characteristics for the model with uncertainty in all the three process parameters.

Table.1. Controller Tuning Parameters

\begin{tabular}{|l|l|l|l|}
\hline \multirow{2}{*}{ Method } & \multicolumn{2}{|l|}{} \\
\cline { 2 - 4 } & \multicolumn{1}{|c|}{$\mathrm{K}_{\mathrm{P}}$} & \multicolumn{1}{|c|}{$\mathrm{K}_{\mathrm{I}}$} & $\mathrm{K}_{\mathrm{D}}$ \\
\hline Arrieta Orozco & 194.15 & 41.86 & 301.73 \\
\hline Syrcos \& Kookos: & 120.18 & 20.23 & 594.55 \\
\hline Fruehauf Method & 74.32 & 13.512 & 137.492 \\
\hline
\end{tabular}

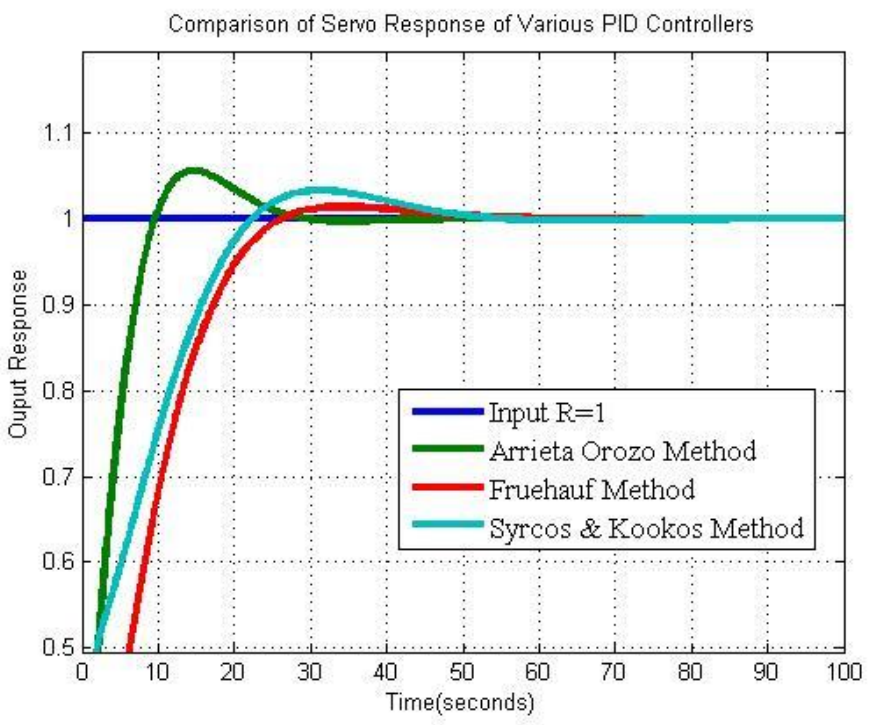

Fig 4. Servo response of level when input setpoint $R=1$

Table.2. Comparison of Closed Loop Response Performance Measure

\begin{tabular}{|l|l|l|l|l|}
\hline $\begin{array}{l}\text { Performance Measure } \\
\text { Method }\end{array}$ & IAE & ISE & ITAE & ISTE \\
\hline Arrieta Orozco & 3.547 & 1.541 & 18.43 & 2.86 \\
\hline Fruehauf Method & 7.907 & 4.114 & 59.65 & 16.98 \\
\hline Syrcos \& Kookos: & 6.113 & 2.189 & 57.58 & 9.463 \\
\hline
\end{tabular}




\section{International Advanced Research Journal in Science, Engineering and Technology}

Vol. 8, Issue 9, September 2021

DOI: 10.17148/IARJSET.2021.8942

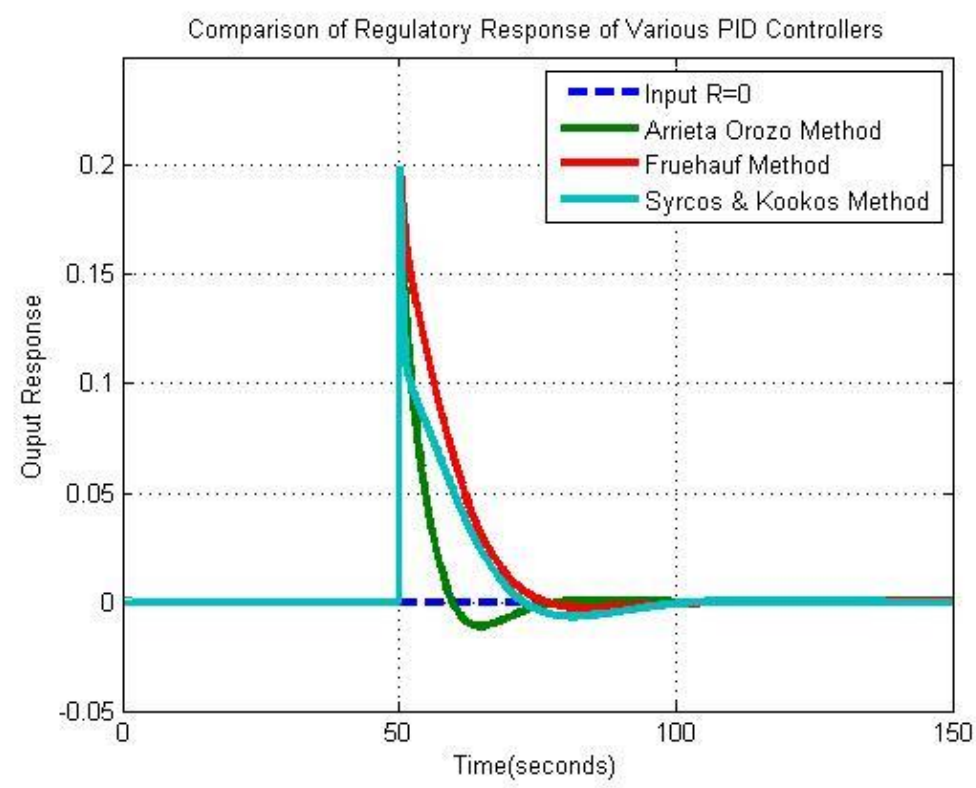

Fig 5. Regulatory response of level when input setpoint $\mathrm{R}=0$ and disturbance at 50 secs

\section{CONCLUSION}

In this work, the simulation studies have been carried out for the identified model of interacting two tank level process using conventional three mode PID controller methods. It is observed that the conventional controller gives better closed loop time domain response and has been validated by measuring the performance index and is tabulated in Table. 2

\section{REFERENCES}

1. J. Rajaraman and J. Sarangan, "Study on Simulation and Design of Various PI Controller for a Non-Interacting Systems: An approach to conventional and computational algorithms", CASTR-VI, pp. 154-159, 2021

2. J.S. Lather and Linkan Priyadarshini, Design of IMC PID controller for a higher order system and ITS Comparison with conventional PID Controller, International Journal of Innovative Research in Electrical, Electronics and Instrumentation Control Engineering, pp. $281-287,2013$.

3. D. Valerio and J.S. Costa, "Tuning of fractional PID controllers with Ziegler Nichols type rules, Signal Processing, pp-2771-2784, 2006

4. Naga Siva Rama Murthy V. "Micro controller based Power Factor Correction". International Research Journal on Advanced Science Hub, 2, Special Issue ICIES 9S, 2020, 108-115. doi: 10.47392/irjash.2020.170

5. Priyanka Singh; Prasad L B. "A Comparative Performance Analysis of PID Control and Sliding Mode Control of Two Link Robot Manipulator". International Research Journal on Advanced Science Hub, 2, 6, 2020, 43-54. doi: 10.47392/irjash.2020.35

6. J.G. Ziegler and N.B. Nichols, "Optimum Settings for Automatic Controllers", Transactions ASME, pp. 7590768

7. K.J. Astrom \& T. Hagglund, "PID Controllers: Theory, Design and Tuning", ISA Publication, 1995.

8. S. Skogestad, "Probably the best PID tuning rules in the world", AICHE Journal, pp. 276-280.

9. Haalman. A, "Adjusting Controllers for dead time processes", Control Engineering, 1965, p71

10. Smith. C. A and Corripio A.B, "Priniciples and practice of automatic process control", 1986

11. Fund H, Wang. C, and Cao.L, Tuning of PID controllers based on gain and phase margin specifications", Automatica, 1995, pp. 497-502.

12. Malwatkar, G.M, A.A. Khandekar and S.D. Nikam, "PID controllers for higher order systems based on maximum sensitivity function", $3^{\text {rd }}$ International Conference on Electronics Computer Technology, 2011. 